\title{
Research on Green Design Based on the Environmental Requirement
}

\author{
Ying $\mathrm{Bai}^{1}$ and Minghai Yuan ${ }^{2,3}$ \\ ${ }^{1}$ Changzhou Institute of Mechatronic Technology, Changzhou 213022, China \\ Bying75@126.com \\ ${ }^{2}$ College of Mechanical and Electrical Engineering, Hohai university, Changzhou, \\ 213022, China \\ ${ }^{3}$ Guangxi Key Laboratory for Manufacturing System and Advanced \\ Manufacturing Technology, Nanning, 530004, China. \\ ymhai@126.com \\ Abstract
}

\begin{abstract}
For the increasingly serious global environmental pollution and rising awareness of environmental protection, a method for green design based on the environmental requirements is put forward. This paper list the basic content based on the environmental requirements. On the grounds of knowledge reuse, the existing products' conformity degree model is built on base of the fuzzy set theory. The fuzzy-analytic hierarchy process $(F-A H P)$ and fuzzy set theory are used todetermine the importance of the product's environmental requirements. n this paper we calculate the determination of the existing product with the each environmental requirement and the comprehensive conformity of the product. Then we can choose the best products to modify the design and achieve the purpose of green design. Finally we give the final green design method based on environmental requirements. In the product on the analysis of the conformity degree of the various environmental requtrements the method combines with the fuzzy analytic hierarchy process and fu $3 y$ set method to effectively choose the best product that highly meets environment requirements to optimize and shorten the design cycle. Taking the design of the CNC machine tool as an example, we can get the validation that the method is an effective method of produc green design.
\end{abstract}

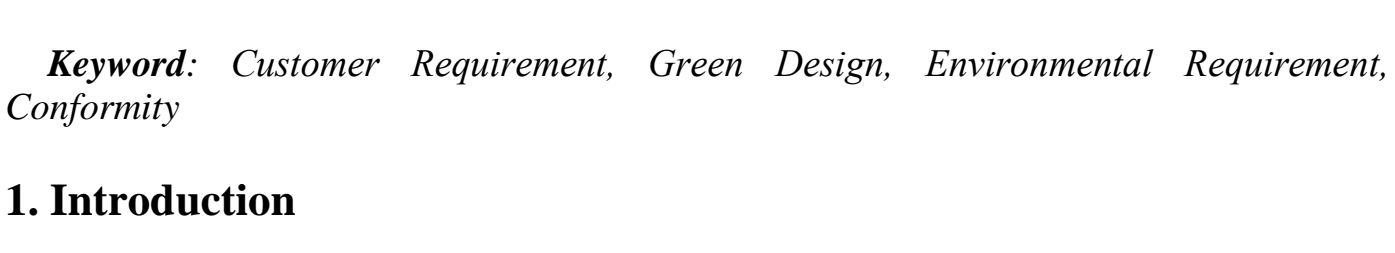

With the progress of society and science technology, the deterioration of the global environment and the continuous improvement of people environmental protection consciousness, the modern production are no longer just limited to meet the customer requirements, gradually to meet the product environmental requirements, and become an inportant part of the production. In order to ensure the quality of human living environment and economic sustainable development, the modern industrial production is paying more and more attention to the "green" index of the products. To develop and design the products that meet the customer requirements and environmental requirements will become an advantage in the fierce competition in the market.

Scholars in and abroad did lots of research on the method of green design. For example, Masui Keijiro, Aizawa Seiichi [1] etc. put forward an improved product green design method called QFDE(Quality function deployment for environment), on the basis of QFD[2], adding the considerations of environmental requirements, and it is mainly used in the initial design stage in the life cycle of products; Kumar Deepak, Simpson Timothy 
W. [3] etc. proposed the design of product family oriented to the market, and this method can be better to meet the diversified demands of the market; Regazzoni D. [4] etc. provided a series of structured criterion of green design on the basis of the TRIZ theory, to help green designers according to the environment of design parameters to improve product design, manufacturing process, service and so on; Gernani M. [5] etc. presented a oriented green design of case-based reasoning (CBR) method, integrating the design criteria and process to enable designers to understand rapidly and effectively, thus speeding up the process of product green design. Recently years, domestic scholars also did some research on it. Z.F. Liu [6] etc. presented the method of green design under mass customization mode, and gave the process and key technology under mass customization mode. Although the methods talked above have done some research on customer requirements and the method of product green design, they were lack of analysis based on the comprehensive consideration of environmental requirements, and couldn't realize the process of green design method that meets environmental requirements, so the research on green design based on environmental requirements is very necessary.

So in this paper, a new product green design method based on environmental requirements is put forward. Based on the knowledge reuse, the paper builds the existing products' conformity model with the fuzzy-analytic hierarchy prôcess (4-AHP) and fuzzy set theory, and then calculates the determination of the existing product line with the each environmental requirement, finally calculates the comprehensive confornity degree of the product. Thus, we can choose the best products to modify the design and at last give the final green design method based on environmental requirements. And in order to prove it is reasonable and practicable, an example of the process of developing a CNC is provided. On the validation, it shows that the method is reasonable and feasible.

\section{Determination of Product Environmental Requirements \\ 2.1. Environmental Requirements Summary}

Environmental requirement [7] is an extremely important part in the analysis of green design demand, and it can be summarized has follows:

(1) Energy: inclüding reducing energy consumption, using the clean, renewable energy, etc.

(2)Resource including reducing the use of the material of serious environmental pollution and the ratio of use of precious and rare materials, and using green material with non-toxic harmless as far as possible, at the same time the material should meet the condition of easily degradable, recyclable, reusable and so on.

(3)Environmental effect: including strictly controlling the emissions of waste in the process of production and use, and the structure of product should permits easy disassembly crushing, burning or landfill disposal, and the impact on the environment as little as possible.

The environmental requirements mentioned above is common, but not for a specific product. Therefore, designers in the process of design should do something to make some necessary modification and improvements for the products in demand according to the specific circumstances of the products, in accordance with the principle of low toxicity, low pollution, recycle, and to get the green design method that has significant effect on environmental demands so as to meet the requirements of the subsequent design. The hierarchy structure of the design is as shown below: 


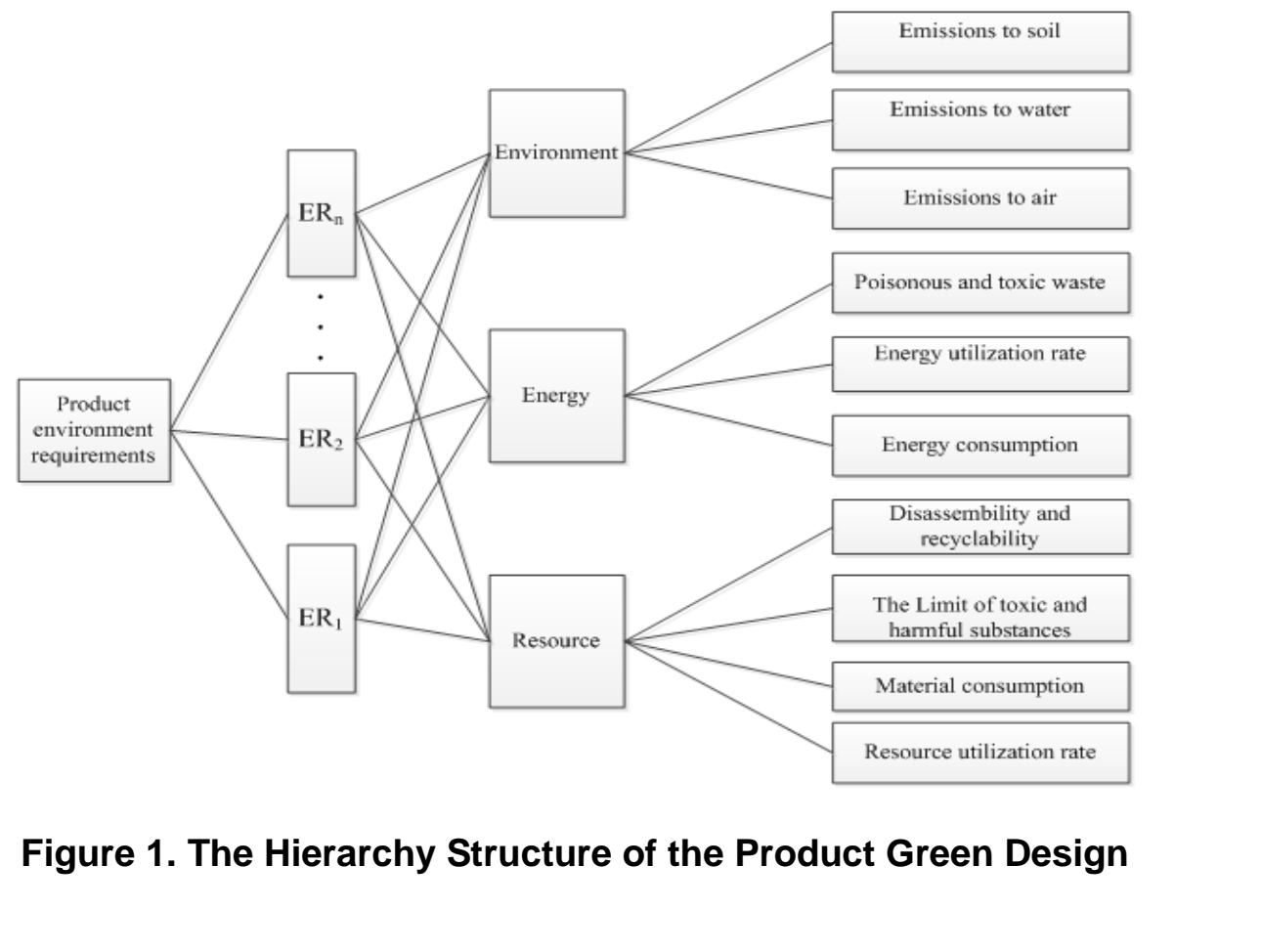

\subsection{Calculation of the Important Degree of Product Envfonmental Requirements}

The important degree of product environmental equirements [8] reflects customer attention to some product environmenodemand levels. For example, some products, customers pay attention to its recyclability, and some products, the customer is to pay attention to its energy consumption Analysis and research on the important degree of product environmental requirements is an important part in the analysis of product green design, and has great significance on product green design, product design needs optimization and the decision planning.

Due to the different products and even the same products under the different conditions of use will have different needs in the environmental demands, or say to the different emphasis on environmental requirements, so that their important degree will be different. So in the process of producl design, we should pay attention to the order in accordance with the different environmental demands and then to treat it accordingly. We should give priority to those environmental needs that must be met and be of great importance. Conversely, for those less important environmental needs can be finally considered. In determining the important degree of environmental demands, there are mainly two ways that are experts identifying method and customers determining method.

The mora commonly used method in experts identifying method is Delphi method, namely, the expert evaluation method; the other method commonly used is the customer survey the methods talked above about the calculation of the important degree have poor interpretation consistency as well as the defects of low efficiency [9][10].

This paper adopts fuzzy-analytic hierarchy process (F-AHP) to determine the important degree of product environmental requirements. The specific steps for the determination of product environmental demands importance with F-AHP method are as follows:

(1) The product environmental requirements are expressed as $E R=\left\{\mathrm{ER}_{1}, \mathrm{ER}_{2}, \ldots, \mathrm{ER}_{m}\right\}$, according to table 1 of $0.1 \sim 0.9$ scale to establish the product environmental demand priority relation matrix $G=\left(\mathrm{g}_{i j}\right)_{m \times m}$, and the matrix $G$ is fuzzy complementary judgment matrix. 
Table 1. Meaning of the Comparison between Two Elements in the 0.1 0.9 Scale

\begin{tabular}{|c|c|c|}
\hline Scale & Definition & Explanation \\
\hline 0.5 & $\begin{array}{l}\text { Equally } \\
\text { important }\end{array}$ & $\begin{array}{l}\text { The comparison of two elements, the same } \\
\text { important. }\end{array}$ \\
\hline 0.6 & $\begin{array}{l}\text { A slightly more } \\
\text { important }\end{array}$ & $\begin{array}{l}\text { An element is slightly more important than the other } \\
\text { one. }\end{array}$ \\
\hline 0.7 & $\begin{array}{l}\text { Obviously } \\
\text { important }\end{array}$ & $\begin{array}{l}\text { An element is significantly important than the other } \\
\text { one. }\end{array}$ \\
\hline 0.8 & More important & An element is more important than the other one. \\
\hline 0.9 & $\begin{array}{l}\text { Extremely } \\
\text { important }\end{array}$ & $\begin{array}{l}\text { An element is extremely more important than the } \\
\text { other one. }\end{array}$ \\
\hline $\begin{array}{l}0.1,0.2 \\
0.3,0.4\end{array}$ & $\begin{array}{l}\text { The reverse } \\
\text { comparison }\end{array}$ & $\begin{array}{l}\text { If the element } i \text { compared with the element } j \text { gets to } \\
\text { the } g_{i j} \text {, then the comparison of judgment between } \\
\text { element } i \text { and element } j \text { is } 1-g_{i j} \text {. }\end{array}$ \\
\hline
\end{tabular}

(2)Convert the priority relation matrix $G=\left(\mathrm{g}_{i j}\right)_{m \times m}$ into fuzzy consistent judgment matrix $V=\left(\mathrm{v}_{i j}\right)_{m \times m}$, and among them:

$$
v_{i j}=\frac{v_{i}-v_{j}}{2 n}+0.2
$$

According to the row to sum, we can get

$$
v_{i}=\sum_{j=1}^{m} g_{i j}, i=1,2,3, \ldots,
$$

(3)According to the fuzzy consistent Gudgment matrix $V$ among the product environmental needs, we can calculate the importance of product environmental demands $\delta=\left\{\delta_{1}, \delta_{2}, \ldots, \delta\right\}$ Matrix $V$ is shown in Table 2:

Table 2. Fuzzy Consistent Judgment Matrix $V$ among Product Environmental Demands

\begin{tabular}{lllllll}
\hline & $E R_{1}$ & $E R_{2}$ & $E R_{3}$ & $\cdots$ & $E R_{m}$ & $L$ \\
\hline$E R_{1}$ & $v_{12}$ & $v_{22}$ & $v_{23}$ & $\cdots$ & $v_{2 m}$ & $l_{2}$ \\
$E R_{2}$ & $v_{31}$ & $v_{32}$ & $v_{33}$ & $\cdots$ & $v_{3 m}$ & $l_{3}$ \\
$E R_{0}$ & $\cdots$ & $\cdots$ & $\cdots$ & $\cdots$ & $\cdots$ & $\cdots$ \\
$E R_{m}$ & $v_{m 1}$ & $v_{m 2}$ & $v_{m 3}$ & $\cdots$ & $v_{m m}$ & $l_{m}$ \\
\hline
\end{tabular}

In Table 2:

$$
\begin{gathered}
l_{i}=\sum_{j=1}^{m} v_{i j}-0.5, i=1,2, \ldots, \mathrm{m} \\
\delta_{i}=\frac{l_{i}}{\sum_{i=1}^{m} l_{i}}=\frac{2 l_{i}}{m(\mathrm{~m}-1)}, i=1,2, m .
\end{gathered}
$$


In the formulate: $\sum_{i=1}^{m} l_{i}=\frac{m(\mathrm{~m}-1)}{2}, \mathrm{~m}-$ the order of matrix

Therefore, the obtained importance of product environmental requirements is expressed as $\delta=\left\{\delta_{1}, \delta_{2}, \ldots, \delta_{m}\right\}$.

In view of the above algorithm, we can use $C R$ (consistency ratio) to check its consistency, and to ensure the reliability of the algorithm. Based on the quality function deployment [11] experience rule: if $C R<0.1$, then we can think the consistency judgment is acceptable; if $C R \geq 0.1$, then we need to make the appropriate adjustments to correct the consistency until it can meet the requirements.

\section{Green Design Based On Environmental Requirements}

In this paper, during the production of products to meet customer demand at the same time, and a product green design method for environment demands is put forward. Firstly, collecting environment requirements, classifying them and an initial environment requirements classification will be built. Secondly, on the grounds of knowledge reuse, the existing products' conformity degree model is built on base of the fuzzy set theory. Thirdly, computing the conformity of each product environment requirements by F-AHP and fuzzy set theory, then we can get the environment composite conformity of each product.

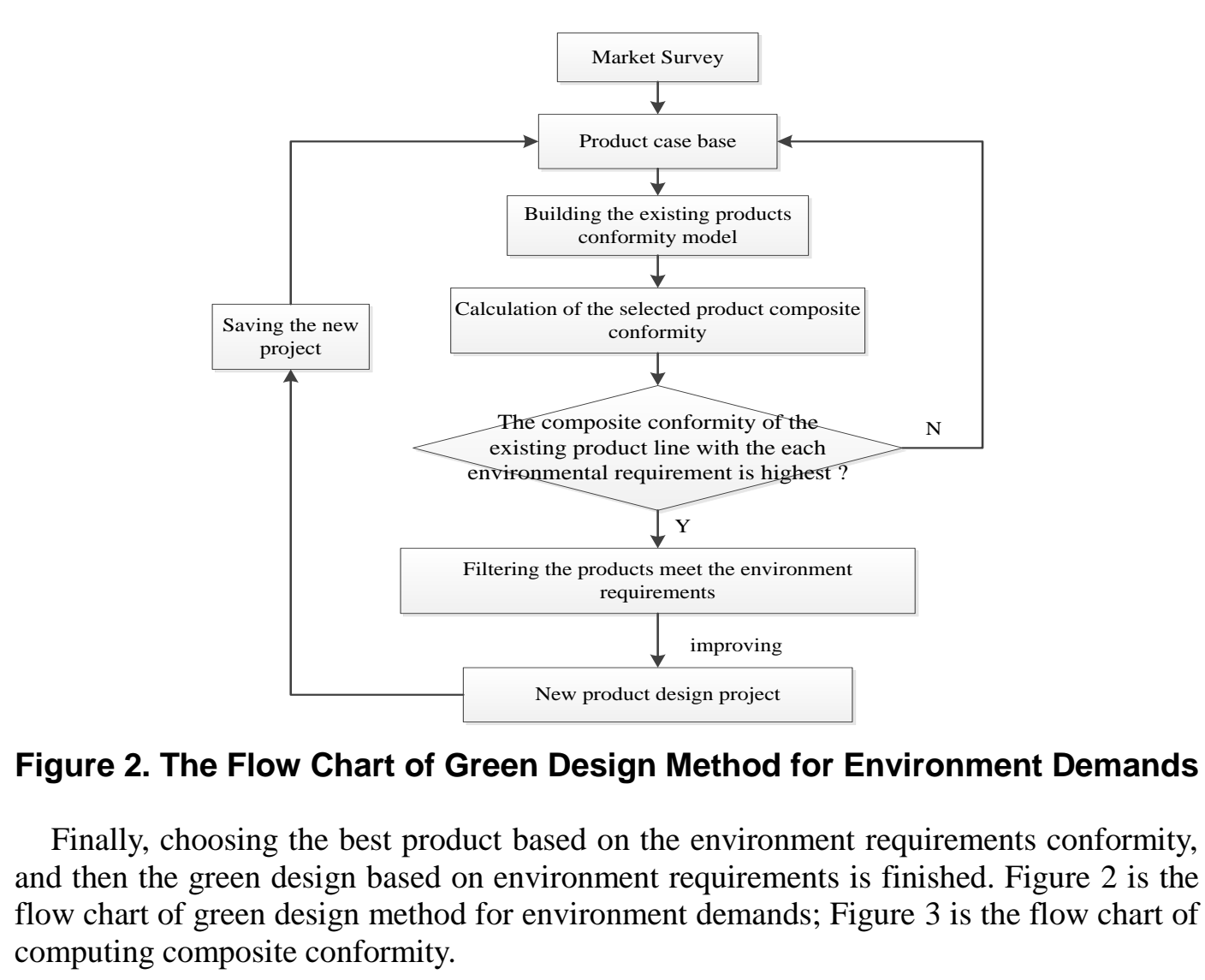




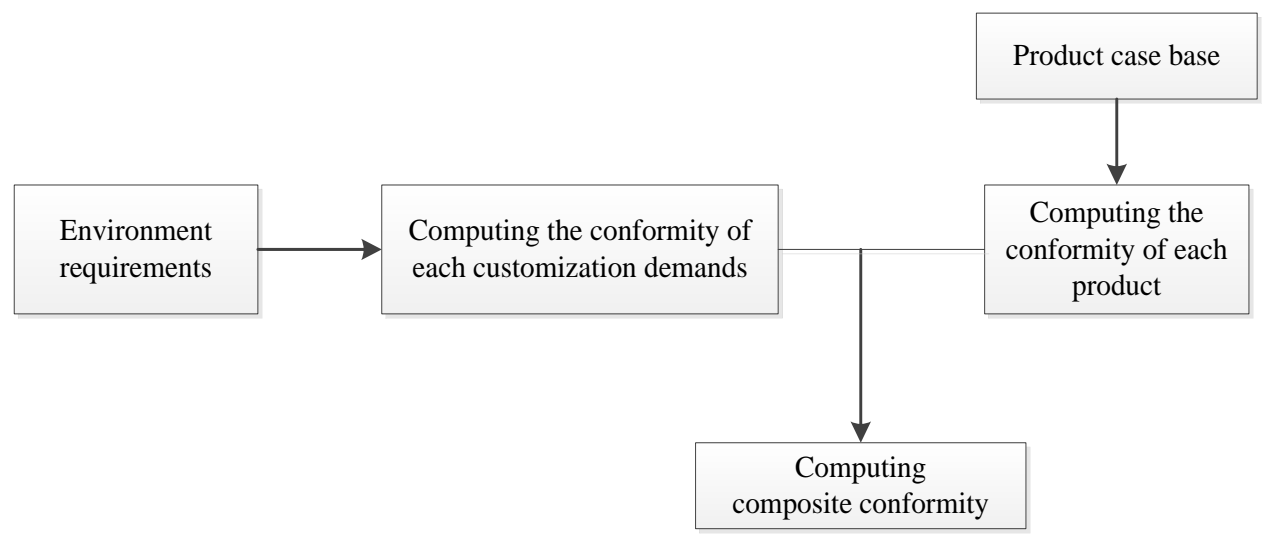

Figure 3. The Flow Chart of Computing Composite Conformity

\subsection{Building the Product Case Base}

Building the product case base [12] is the first step to realize rapid greent design, and to express case precisely is the key point.

$$
\begin{gathered}
\mathrm{S}_{\mathrm{n}}=\left\{\mathrm{C}_{1}, \mathrm{C}_{2}, \cdots, \mathrm{C}_{\mathrm{n}}\right\} \\
C_{n}=\left\{\mathrm{ER}_{1}, E R_{2}, E R_{3}, \mathrm{ER}_{4}, \mathrm{ER}_{5}, \mathrm{ER}_{6}\right.
\end{gathered}
$$

$\mathrm{S}_{\mathrm{n}}$ is the case base, $\mathrm{C}_{\mathrm{n}}$ is the $\mathrm{n}$ case in the case base. In the example verification part, this paper takes the design process of $\mathrm{CNC}$ for example, $E R_{1}, E R_{2}, \ldots, E R_{6}$ represents 6 items of environment demands and builds a case base according to the existing 6 kinds of environment demands to testify this method is reasible and effective.

\subsection{Building the Existing Products Conformity Model Based On Fuzzy Sets Theory}

According to the knowledge reuse, can select the existing appropriate product from product database to calculate the conformity degree of customer and environmental needs. $X$ is a linguistic variable "conformity". This paper sets linguistic variable as $H(\mathrm{X})=\{$ don't meet, not fally meet, meet, all most meet, fully meet $\}$ to represent the existing ptoduct's conformity to the environmental requirements. And we select the distribution form of triangle membership function to express. $X_{1}, X_{2}, X_{3}$, $X_{4}, \quad X_{5}$ correspond to each linguistic variable respectively and they stand for those true values, and then we can take the domain $\mathrm{U}$ as a closed interval $[0,1], u \in U$. In order to calculate conveniently, we can use three triple $(\mathrm{n}, \alpha, \beta)_{L R}$ to represent a fuzzy number.

Definition: Triangular fuzzy number can be used a three triple $\mathrm{F}(\mathrm{n}, \alpha, \beta)$ to express, mong that $\mathrm{n}$ stands for the fuzzy number median, $\alpha, \beta$ respectively represent the left and ght span of fuzzy number, and its membership function is expressed as:

$$
f(\mathrm{x})=\left\{\begin{array}{l}
\frac{1}{\alpha}(\mathrm{x}-\mathrm{n})+1 \\
\frac{1}{\beta}(\mathrm{n}-\mathrm{x})+1
\end{array}\right.
$$

Membership function curve is shown in Figure 4: 


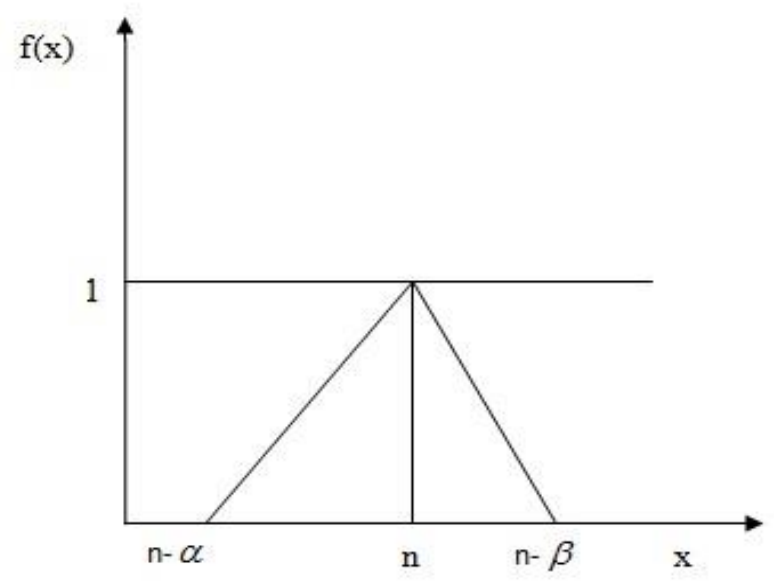

Figure 4. Membership Function Curve

Therefore, the fuzzy number of product conformity degree can be expressed with a three triple $X_{i}=(\mathrm{n}, \alpha, \beta)_{L R}$, and its curve is shown in Figure 5 ) Among hat $X_{1}, X_{2}$,

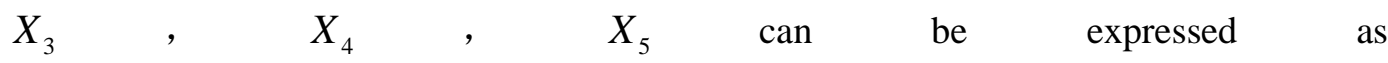
$X_{1}=(0,0,0.25)_{L R} \quad, \quad X_{2}=(0.25,0.25,0.25)_{L R}, \quad X_{3}=(05,0.25,0.25)_{L R} \quad$, $X_{4}=(0.75,0.25,0.25)_{L R}, X_{5}=(1,0.25,0)_{L R}$ Then wer canget the conformity of each product, setting as $X_{\mathrm{ij}}$.

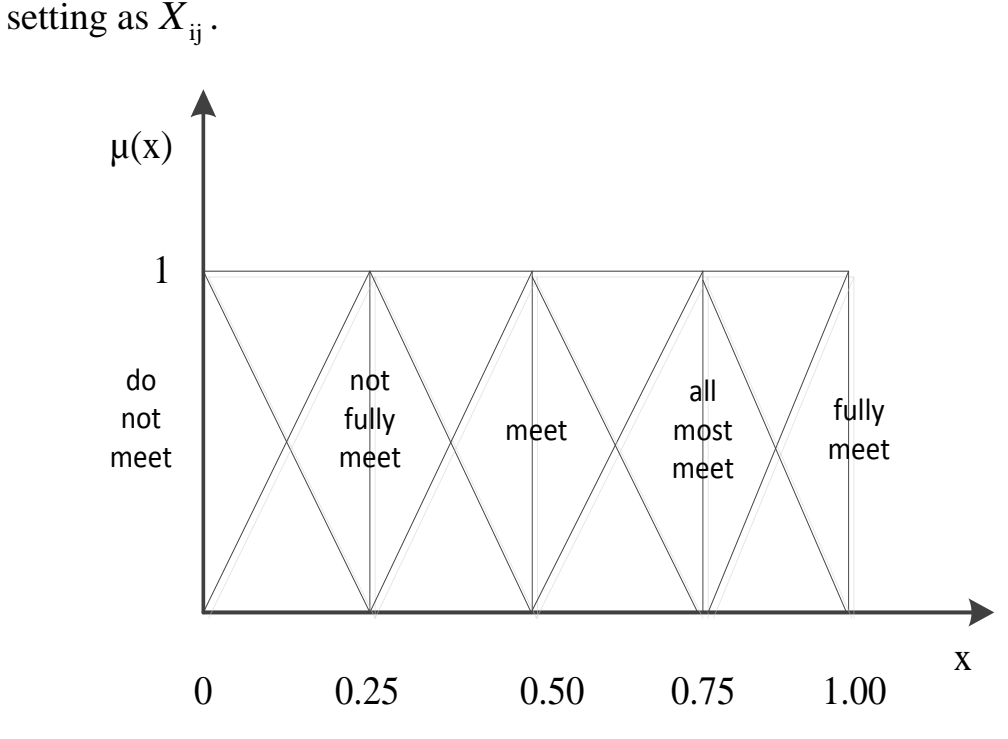

Figure 5. Fuzzy Number Curve of True Value to Product Conformity

\subsection{Calculation of Product Composite Conformity}

Assuming that $Q_{i}$ corresponds to environmental requirement composite conformity of the number $i$ product. And $X_{\mathrm{ij}}$ stands for the number $\mathrm{j}$ environmental requirement conformity of the number $i$ product. And $Q_{i}$ is expressed as:

$$
Q_{i}=\sum_{j=1}^{m} \delta_{j} \times X_{i j}, i=1,2, \ldots, \mathrm{Z}, \mathrm{j}=1,2, \ldots, \mathrm{m}
$$

Environmental requirement conformity of each product is shown in the Table 3: 
Table 3. Product Environmental Requirement Conformity

\begin{tabular}{|c|c|c|c|c|c|}
\hline & & \multicolumn{4}{|c|}{ conformity } \\
\hline $\begin{array}{l}\text { Environmental } \\
\text { demands factor }\end{array}$ & importance & Product 1 & Product 2 & $\ldots$ & Product Z \\
\hline$E R_{1}$ & $\delta_{1}$ & $X_{11}$ & $X_{21}$ & $\ldots$ & $X_{Z 1}$ \\
\hline$E R_{2}$ & $\delta_{2}$ & $X_{12}$ & $X_{22}$ & $\ldots$ & $X_{Z 2}$ \\
\hline .. & $\ldots$ & $\ldots$ & $\ldots$ & $\ldots$ & $\ldots$ \\
\hline$E R_{m}$ & $\delta_{m}$ & $X_{1 m}$ & $X_{2 m}$ & $\ldots$ & $X_{Z m}$ \\
\hline $\begin{array}{l}\text { Product } \\
\text { requirements } \\
\text { conformity } Q_{i}\end{array}$ & $\begin{array}{r}\text { environmental } \\
\text { composite }\end{array}$ & $\sum_{j=1}^{m} \delta_{j} \times X_{1}$ & $\sum_{j=1}^{m} \delta_{j} \times X_{2}$ & $\cdots$ & $\sum_{j=1}^{m} \delta_{j} \times X_{Z_{j}}$ \\
\hline
\end{tabular}

Because $Q_{i}$ is a fuzzy number, so the calculated number will also be a fuzzy number, and its three triple form is $Q_{i}=\left(\mathrm{n}_{i}, \alpha_{i}, \beta_{i}\right)$. So $n_{i}=\sum_{j=1}^{m} \delta \times n_{i j}, \alpha_{i}=\sum_{j=1}^{m} \delta_{j} \times \alpha_{i j}$, $\beta_{i}=\sum_{j=1}^{m} \delta_{j} \times \beta_{i j}$, and in the formulate, $n_{i j}$ stands for the number $j$ environmental requirement conformity of the number $i$ product $\alpha_{i j}$ stands for the number $j$ environmental requirement conform ty of the number $i$ product, $\beta_{i j}$ stands for the number $j$ environmental requirement eonformity of the number $i$ product.

According to the calculated results, we can sefect a product among that to modify the design. And we should judge the product conformity based on environmental requirement, then to select the best products to improve the design and so as to quickly reach the purpose of green design.

\section{Example Verification}

Taking the design of a CNC machine tool as an example, this paper is to verify the green desgn method based on the environmental requirements. The product environmental requirements obtained from the market survey, through the standard processing, can be summed up to 6 items as low energy consumption, high efficiency, low noise, and recovery, less wear and tear, complying with the relevant environmental protection law, and they respectively correspond to the environmental needs $E R_{1}$, $E R_{2}, \cdots, E R_{6}$. The fuzzy consistent judgment matrix $V$ is established in this kind of $\mathrm{CNC}$ machine tool's product environmental requirements with the fuzzy analytic hierarchy process. That's the Table 4.

Table 4. Fuzzy Consistent Judgment Matrix $V$ of Product Environmental Requirements of CNC Machine Tools

\begin{tabular}{lccccccc}
\hline & $E R_{1}$ & $E R_{2}$ & $E R_{3}$ & $E R_{4}$ & $E R_{5}$ & $E R_{6}$ & $L$ \\
\hline$E R_{1}$ & 0.48 & 0.53 & 0.65 & 0.52 & 0.60 & 0.57 & 2.85 \\
$E R_{2}$ & 0.50 & 0.47 & 0.65 & 0.52 & 0.58 & 0.59 & 2.81 \\
$E R_{3}$ & 0.39 & 0.41 & 0.49 & 0.40 & 0.46 & 0.42 & 2.07 \\
$E R_{4}$ & 0.45 & 0.44 & 0.58 & 0.51 & 0.54 & 0.50 & 2.52 \\
\hline
\end{tabular}




\begin{tabular}{llllllll}
\hline$E R_{5}$ & 0.38 & 0.42 & 0.51 & 0.48 & 0.52 & 0.42 & 2.23 \\
$E R_{6}$ & 0.44 & 0.46 & 0.59 & 0.50 & 0.55 & 0.51 & 2.55 \\
\hline
\end{tabular}

According to the Eq. 4, we can calculate the importance of product to each environment, and the result is $\delta=\{0.190,0.187,0.138,0.168,0.149,0.170\}$. Then we will verify the consistency of the judgment matrix, and get the consistency ratio $C R<0.1$, so we can consider the algorithm's consistency is acceptable, and reliability can be satisfied.

Then, according to the Eq. 8, calculating the product environmental requirements composite conformity, we can get the result that is $Q=\{0.554,0.547,0.426,0.499,0.451,0.504\}$.

After stepwise screening and comparison, we can find that the product composite conformity of the environmental demand $E R_{1}$ is highest. According to experience the fuzzy number median $m$ is larger, the composite conformity is higher; when the ruzzy number median $m$ is equal or similar, and we can compare the left span and right span of the fuzzy number. The deviation between the left span and right span is maller, the higher product conformity will be. According to the product conformity, we can get the highest conformity product, and then to modify the design so that can quickly design the green products that meet the environmental requirements. The design process indicates that the green design method based on the environmental requirements is feasible.

Finally, sift the best project from case base, then develop the project, get the final project and save it into case base.

\section{Conclusion}

According to the growing impertance of the environmental requirements, this paper puts forward a green design method based on en vironmental demands. On the grounds of knowledge reuse, the paper uses fuzzy analytic hierarchy process and fuzzy set theory to determine the importance of the product environmental requirements, and then to calculate the determination of the existing product with the each environmental requirement, and finally calculate the composite conformity of the product. Thus, we can choose the best roduct to improve and make it meet the environmental demands, like this we can quickly achieve the purpose of product green design. The method is verified by the design of CNC machine tools.

While there are aloo sone shortcomings, in this paper, the problems such as collecting environment requinements, the items of these demands, solving contradiction and so on haven't been talk about. These problems are also very important to green design and should be deeply studied.

\section{Acknowledgement}

This work was supported by the Jiangsu province university "Blue Project" excellent young backbone teachers' project in 2014, and the open fund of Guangxi Key Laboratory for manufacturing system and advanced manufacturing technology under Grant number 13-051-09S09. 


\section{Reference}

[1] M. Keijiro, A. Seiichi, S. Tomohiko and I. Atsushi, "Quality function deployment for environment: QFDE", 7th Design for Manufacturing Conference; Florida, American, (2002).

[2] L P. Sullivan, "Quality function deployment", Quality Progress, vol. 6, no. 19, (1986).

[3] K. Deepak, C. Wei and S. Timothy W, "A market-driven approach to product family design", International Journal of Production Research, vol. 3, no. 47, (2009).

[4] D. Regazzoni, C R and D. Russo, “TRIZ-Driven Eco-Design and Innovation”, ICODE 09: Proceedings of the 2nd International Conference on Research into Design; Bangalore, India, (2009).

[5] M. Gernani, M. Mandolini and H. Marconi, Editor, "A Case-Based Reasoning Approach to Support the Application of the Eco-Design Guidelines", New York: Springer, (2013).

[6] Z.F. Liu, Y. Jiang, L. Zhang and D. Hu, "Research on green design method for mass customization", China Sciencepaper Online, vol. 8, no. 5, (2010).

[7] X.L. Song, J. Bao and X.H. Liu, "The study and summarization of pivotal technology used in electromechanical products with environmental design", Friend of Science Amateurs, vol. 6, no. 2, (2010).

[8] M.S. Yang and Z.H. Lin, "Method to determine importance of customers' requirements in QFD", Journal of Management Science in China, vol. 5, no. 6, (2003).

[9] S.K. Wei, S.J. Li and Y. Li, "Confirming weight of voice of the customer in QFD using the method of AHP”, Mechanical design \& Manufacture, vol. 6, no. 6, (2005).

[10] Y. Yang and Z.B. Ou, "Customer requirements analysing and processing oriented product green design", China Market, vol. 10, no. 10, (2011).

[11] H.E. Liu, L.P. Zhang, A.D. Che and J.H. Sun, "Improved quality function deployment AI ) A systematic approach", System Engineering-Theory \& Practice, vol. 2 no. 20, (2000).

[12] Y. Li , L.Z. Lu and S.G. Hu, "Research on products rapid green design model integrated CBR, TOC and TRIZ”, Mechanical Science and Technology, vol. 12, no. 31 (2012).

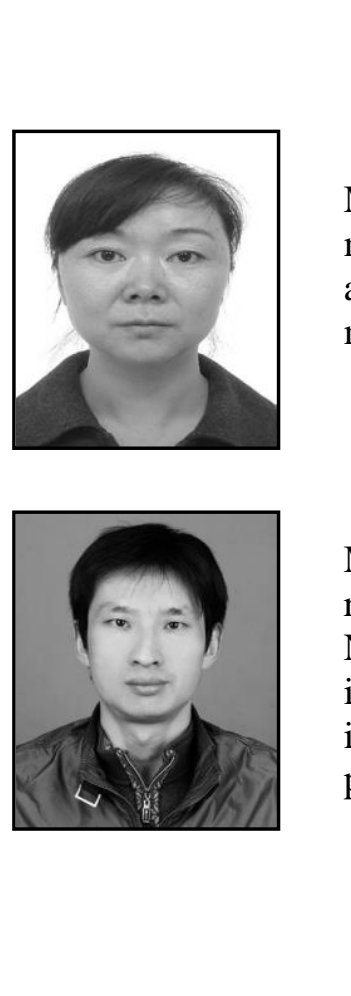

\section{Authors}

Ying Bai, she fs an Associate professor in Changzhou Institute of Mechatronic Technology, China. She received the master degree in mechanical engheering at Guangxi. His research interests are in the areas of digital design and manufacturing including advanced manufacturing system, product design, etc.

Minghai Yuan, he is an Associate Professor in College of Mechanical and Electrical Engineering, Hohai University, China. He receiyed the $\mathrm{PhD}$ degree in mechanical engineering at Danjing University of Science and Technology. His research interests are in the areas of digital design and manufacturing including advanced manufacturing system, Cloud manufacturing, product scheduling, etc. 